Bult. Maicr. Sci. Vol. 2, Number 3, November 1981, pp. 381-388. o Printed in India.

\title{
Scanning electron microscopic fractography of permanent moulded cast iron
}

\author{
S SEETHARAMU and MALUR N SRINIVASAN \\ Department of Mechanical Engineering, Indian Institute of Science, \\ Bangalore 560012 . India \\ MS received 1 February 1981
}

\begin{abstract}
The fracture susceptibility of chill-free permanent moulded cast iron is discussed in terms of graphite configuration. The details of fracture surface topography as revealed by scanning electron microscope examination on areas of slow crack growth and fast fracture are presented and the usefulness of these SEM fractographs in categorizing the fracture modes is demonstrated.
\end{abstract}

Keywords. Permanent moulding; cast iron; graphite; pearlite; fracture toughness; crack size factor; scanning electron microscope.

\section{Introduction}

Permanent moulding process offers several advantages such as faster rates of production, improved dimensional stability, improved surface finish, etc. as compared to the conventional sand-casting process. However, when cast iron of hypo-eutectic composition, normally suited to sand castings, is poured into permanent moulds, it tends to chill heavily necessitating a mandatory heat treatment before use. It is therefore customary to use an iron of hypereutectic composition, usually achieved by raising the silicon content in permanent moulded cast iron, if it is desired to produce chill-free castings. But raising the silicon level to achieve hyper-eutectic composition would have the effect of increasing the hardness and the yield strength of the matrix which could promote brittle-like behaviour in the alloy, even in the case of spheroidal graphite cast iron (Angus 1976). The latter is known to possess good ductility when produced using an iron of hypo-eutectic composition in sand moulds. It is well-known that in brittle alloys catastrophic failure can occur in the presence of defects which contribute towards raising of stress level in their vicinity. For fail-safe design it is recognised that knowledge of critical defect size is very important. The latter would of course depend upon the fracture toughness of the alloy which in turn is a function of the structure and the consequent mechanical properties of the alloy.

An experimental investigation was therefore carried out by the authors to assess the fracture toughness of permanent moulded cast iron as affected by microstructural variations. The latter were brought about by variations in cooling rate of the castings and the melt treatment prior to pouring. As it is 
known that SEM fractograph can be very useful in categorizing the modes of fracture, (Fellows et al 1974), this technique was used extensively in the present work. In this paper, the fracture susceptibility of the castings as affected by graphite configuration is discussed in terms of the fracture toughness parameters as well as the details observed in SEM fractographs.

\section{Experimental}

The base iron used in the present work had a composition as follows: carbon$3.6 \%$; silicon - $3.0 \%$ and sulphur - $0.025 \%$. Molten cast iron was treated with nickel-magnesium alloy with $12 \%$ magnesium with intent to produce spheroidal graphite in the structure. It was observed that with this procedure the graphite configuration could either be spheroidal or irregular at different cooling rates of the casting. Thus it was possible to produce graphite of three basic configurations viz. flake (without nodularizer treatment), spheroidal and irregular graphite in these castings and representative castings from each category were chosen for fracture toughness study.

The fracture toughness values of all these castings were determined following the standard method ASTM-E399-78a. The damage tolerance potential in each casting was assessed using calculated values of the crack size factor which is directly related to the critical defect size. The crack size factor (CSF) is given by

$$
\mathrm{CSF}=1000\left(\mathrm{~K}_{\mathrm{tc}} / \sigma_{\mathrm{Y}}\right)^{2} \mathrm{~mm}
$$

where $\mathrm{K}_{\mathrm{Ic}}$ is fracture toughness in $\mathrm{MN} \mathrm{m}^{-3 / 2}$ and $\sigma_{\mathrm{v}}$ is yield strength in $\mathrm{MN} \mathrm{m}^{-2}$. Fractographs of broken samples were recorded using a Cambridge S-150-2 scanning electron microscope.

\section{Results and discussion}

Typical optical photomicrographs of castings with spheroidal graphite, irregular graphite and flake graphite are shown in figures 1,2 and 3 . The fracture toughness values of these castings were $38.5,36.7$ and $18.5 \mathrm{MNm}^{-3 / 2}$ respectively. Thus, while the presence of irregular graplite appears to have only a marginal effect in reducing the fracture toughness, the presence of flake graphite appears to be very detrimental in this respect. Typical SEM fractographs of broken fracture toughness specimens are shown in figures 4 to 8 . It may be observed that in magnesium-treated iron castings, crack propagation occurs first in a sub-critical fashion (stable crack growth, figures 4 and 6 ) and is subsequently followed by fast unstable fracture. The mode of stable crack growth and unstable fracture is similar in castings containing either spheroidal graphite or irregular graphite. In both these cases crack propagation is preceded by limited void growth around graphite and the subsequent coalescence of these voids occurs with very limited deformation of the inter-graphite bridge. The fast fracture which follows the above is featured predominantly by transgranular cleavage cracks (figures 5 and 7 ). 

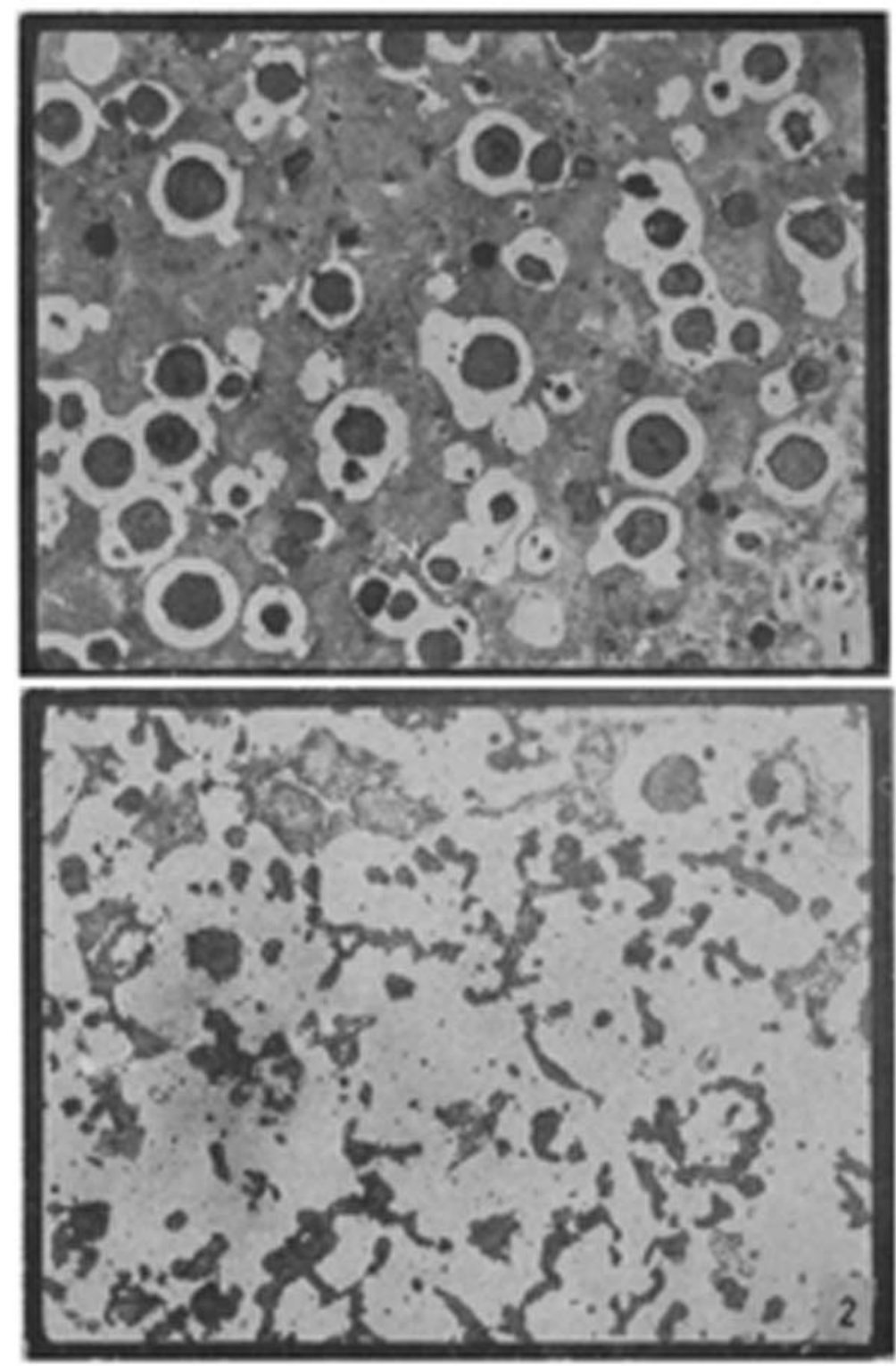

Figures 1-2. Optical microstructure $(\times 200)$ of casting with 1. Spheroidal graphite. 2. Irregular graphite 


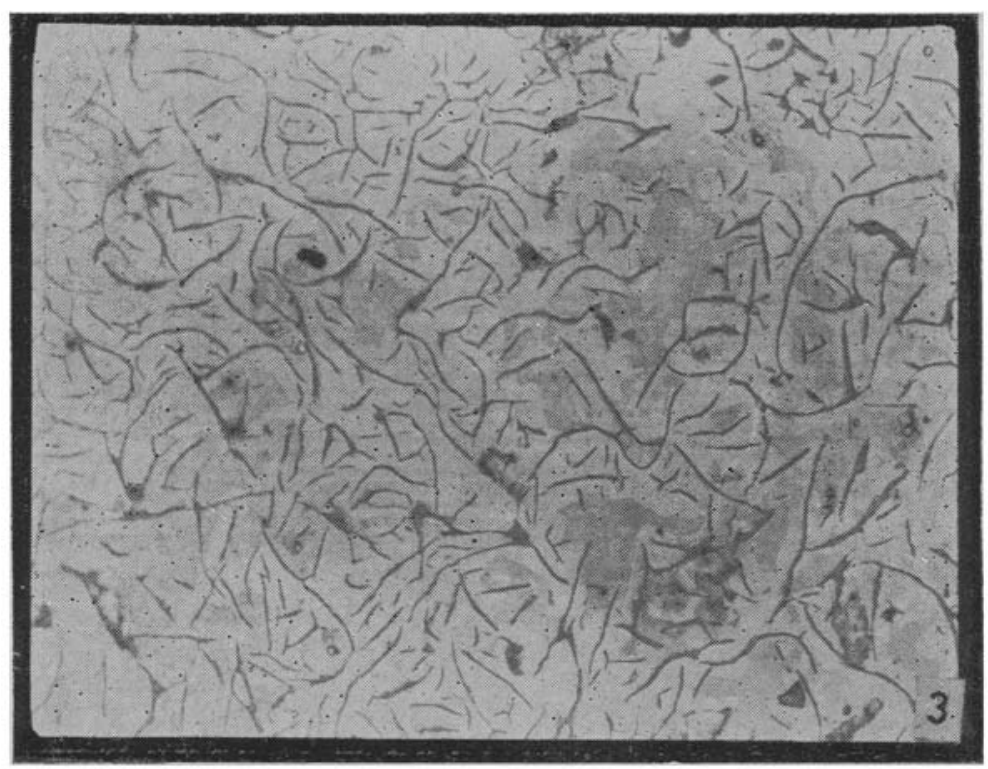

Figure 3. Optical microstructure $(\times 200)$ of casting with flake graphite 


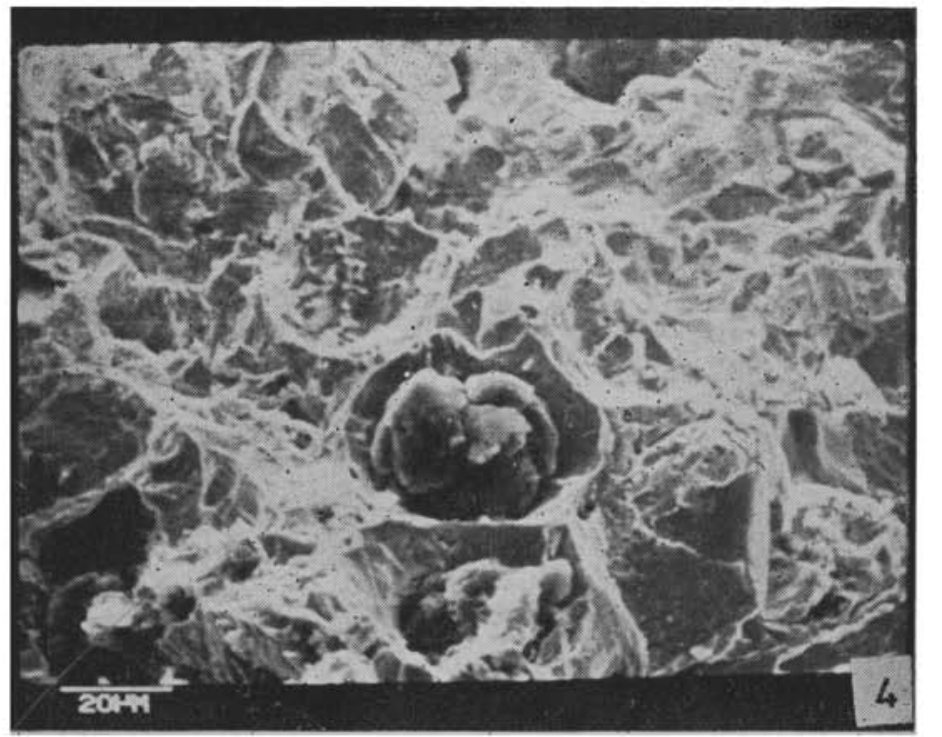


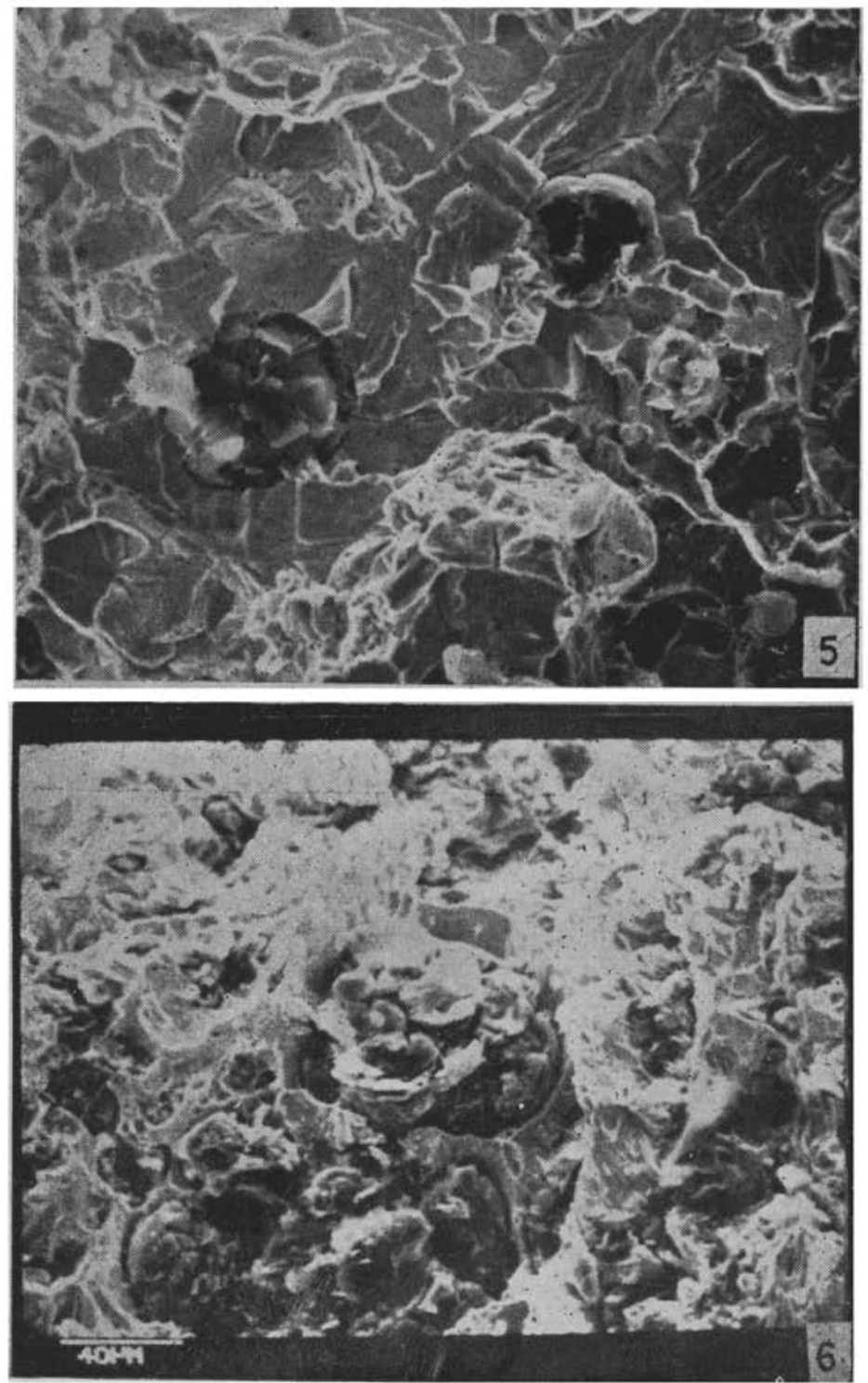

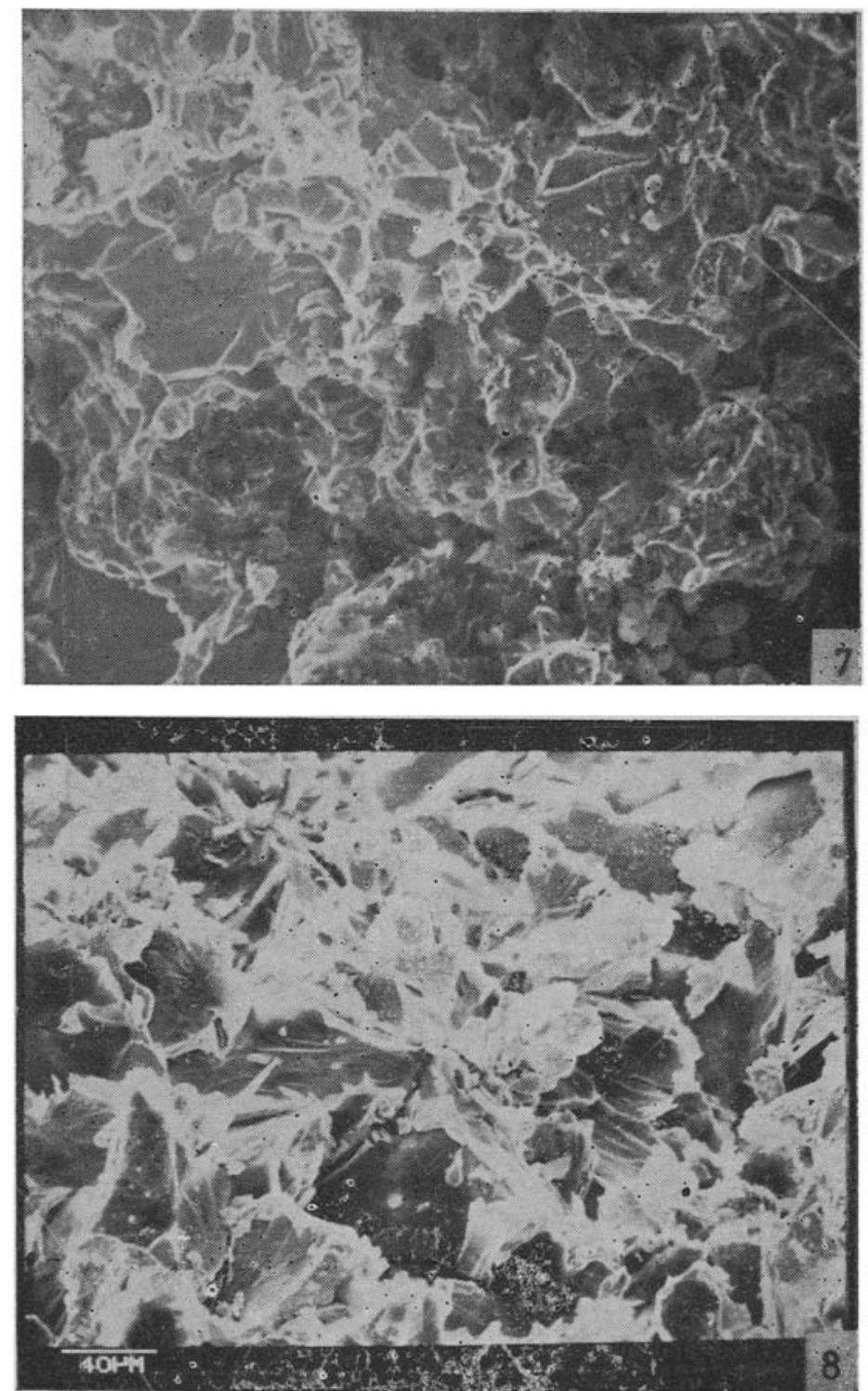

Figures 7-8. SEM fractograph of casting with 7. Irregular graphite, fast fracture region, $(\times 500)$. 8. Flake graphite $(\times 275)$. 
In ligure 8 is shown the fractograph of the casting with flake graphite in which it is seen that the coalescence of graphite-nucleated micro-cracks occurs with very limited plastic deformation of the matrix. The morphology of graphite llakes has masked the details on the fractograph, but the differences in the graphite-matrix interface compared to the previous fractographs may be clearly observed. The absence of void formation around graphite flakes suggests that the onset of microcracks ahead of the graphite flakes must have occurred at low microscopic strain compared to the magnesium-treated irons. Thus, while the smooth graphite-matrix interface as observed in figures 6 and 7 for castings with irregular graphite appears to be innocuous from fracture toughness point of view, the sharp flakes appear to weaken the matrix and promote susceptibility to brittle fracture. The observed fracture toughness values lend support to this viewpoint. In magnesium-treated castings, it was found by etching studies that the bulk of pearlitic matrix was enriched in silicon compared to ferrite around the graphite nodules. In castings having irregular graphite certain amount of redistribution of silicon to the graphitic regions was observed and the possible increase in the fracture resistance of the matrix due to the resulting lower silicon content in the matrix appears partly to contribute to the fracture toughness of these castings.

\section{Crack size factor}

The calculated values of crack size factor which is directly related to the damage tolerance of defects are $4.9,7.4$ and $8.5 \mathrm{~mm}$ respectively for castings with spheroidal graphite, irregular graphite and flake graphite at their respective yield loads. It can be seen that the casting having flake graphite, despite its inherent defective structure, possesses the maximum damage tolerence capacity. However, when the damage tolerance capacity is evaluated for each casting for a given stress, say $200 \mathrm{MN} / \mathrm{m}^{2}$ which corresponds to the failure strength of casting with flake graphite, the crack size factor will be around $37.1,33.5$ and $8.5 \mathrm{~mm}$ respectively for the castings with spheroidal graphite, 1rregular graphite and flake graphite. This further illustrates the superiority of magnesium-treated iron casting for a given component at a given stress.

\section{Conclusions}

(i) The presence of irregular graphite in the microstructure appears to have negligible effect upon the fracture toughness of chill-free magnesium itreated cast iron.

(ii) The presence of flake graphite brings down the fracture toughness value considerably.

(iii) Whilst the damage tolerance potential of casting with flake graphite is higher than the magnesium-trested iron castings, the usefulness of such castings is restricted by the lower strength of the matrix due to the presence of sharp flakes. 
(iv) SEM fractography is very useful in categorizing the modes of fracture in these castings and in throwing light on the active micromechanics operating during fracture.

\section{References}

Angus 1976 H T Cast iron: Physical and engineering properties (London: Butterworths) Fellows J A et al 1974 Metals Hand Book; fractography and atlas of fractography (American Society for Metals, Metals Park, Ohio) Vol. 953 